\title{
RESEARCH OF FEATURES OF PERSONNEL-MARKETING ON THE BASIS OF COGNITIVE MODELING
}

\section{A.V. NIKITINA, L.N. ZAHAROVA, B.B. LOBANOVA \& G.G. VUKOVICH}

Kuban state University, 149 Stavropol'skaya Str., Krasnodar, 350040, Russia

\begin{abstract}
Purpose. Human resources management remains an important area of modern enterprise strategy, as the role of personnel increases in high-tech production, and the highest requirements are placed on competencies. The goal of personnel-marketing is to influence the choice of profession and place of work. Labor carrier-the buyer evaluates and makes a decision about choosing a workplace depending on how much the workplace actualizes his ability to work and meets his expectations as an employee. Biscussion. Note that the choice of a job occurs twice: when the candidate sends a resume to the company and when the candidate makes a decision after the interview. The development prospects of any enterprise are closely linked to existing market trends, knowledge of which helps to choose the appropriate strategy and directions for the development of competencies and the distribution of labor resources. Results. These circumstances actualize the study of the concept of personnel marketing, which is especially important in the context of increasing market uncertainty (sanctions, sanitary and epidemiological restrictions, etc.).

KEYWORDS: Personnel-Marketing; Personnel Management; Cognitive Modeling; Labor Market; Cognitive Maps; Profitability of Personnel Labor; Development of Competencies; Innovative Approach; HR-Technologies; Selection and Selection of Personnel
\end{abstract}

Received: May 26, 2020; Accepted: Jun 16, 2020; Published: Jul 24, 2020; Paper Id.: IJMPERDJUN2020440

\section{INTRODUCTION}

As an interdisciplinary field in modern innovative marketing, a cognitive personnel marketing is developed at the intersection of personnel marketing and cognitive psychology. Modernization of modern HR marketing is possible through its interdisciplinary interaction with economic sociology, economic psychology, cognitive psychology, logistics and enterprise Economics. Interdisciplinary research expands the problem field of personnel marketing and allows us to reflect the holistic and systemic relationships that exist between participants in the internal labor market. Today, the development of the theory and practice of cognitive personnel marketing in both theoretical and practical aspects is at an early stage. The key task of personnel marketing is to analyze and control the situation on the labor market in order to effectively cover the need for personnel and implement organizational, technological, financial, economic, and social and labor goals of the enterprise. The study of personnel marketing based on cognitive modeling is of particular interest to the business community, because there is no unified system of cognitive knowledge about how thinking works and what laws govern the perception and attention of personnel. The purpose of this research is to consider cognitive modeling and determine the possibilities of its use in the concept of personnel marketing as a tool for creating competitive advantages of enterprises, as well as modeling the behavior of HR managers in the context of modern socio-economic challenges.

As an interdisciplinary field in modern innovative marketing, a cognitive personnel marketing is developed at the intersection of personnel marketing and cognitive psychology. Modernization of modern HR marketing is 
possible through its interdisciplinary interaction with economic sociology, economic psychology, cognitive psychology, logistics and enterprise Economics. Interdisciplinary research expands the problem field of personnel marketing and allows us to reflect the holistic and systemic relationships that exist between participants in the internal labor market.

\section{METHODS}

In personnel marketing, methods are used that are a synthesis of marketing and personnel management methods. The main difference between personnel marketing and classical methods of personnel management is that personnel marketing consider the labor market as a sphere that operates according to market laws, which allows personnel marketing to increase the competitiveness of the enterprise. Today, the entrepreneurial-market approach prevails in working with personnel, in which labor, its conditions and jobs are considered as marketing products. In our opinion, it is legitimate to talk about two main principles of personnel marketing. The first involves considering the tasks of personnel marketing in a broad sense. In this case, a personnel marketing refers to a certain philosophy and strategy of human resource management. Personnel are considered as external and internal clients of the company. The goal here is to optimize the use of human resources by creating the most favorable working conditions that help to increase its efficiency and develop staff loyalty to the company's top management. This is a "sale" of the company to its staff. This is why the first principle of personnel marketing is based on market thinking, which distinguishes it from the concepts of personnel management.

The second principle assumes the interpretation of personnel marketing in a narrow sense as a function of the personnel management service, which includes: monitoring external and internal factors that determine the direction of marketing activities and the implementation of the personnel marketing program.

The difference between the principles is that a broad interpretation of personnel marketing implies its attribution to one of the elements of the personnel policy of the enterprise, implemented through the solution of the tasks of the personnel management service. In a narrow sense, a personnel marketing involves the allocation of special activities of the personnel management service related to its information function.

Recruitment, selection, and hiring of company personnel require the use of innovative methods of personnel marketing. We will present an overview of traditional approaches to HR marketing in the form of a cognitive graph, highlighting the marketing approach (Figure 1).
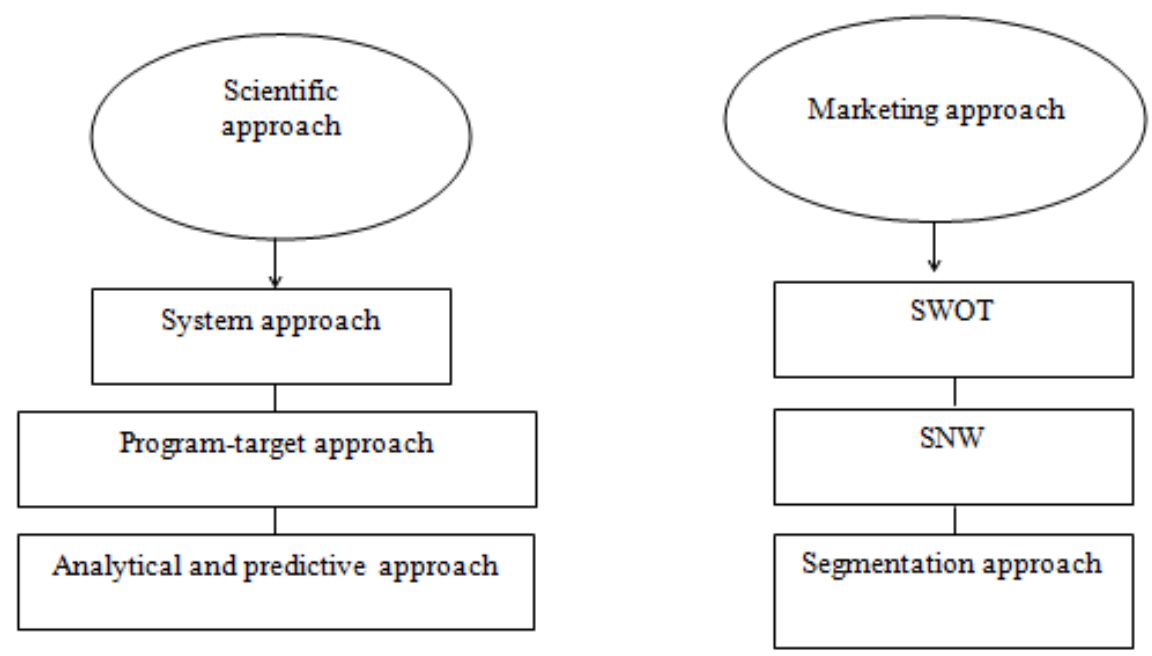

Figure 1: Personnel Marketing Approaches. 
The HR marketing approaches presented by us are characterized by special application boundaries, advantages and disadvantages. Scientific approaches allow us to consider the market situation as an object of study that has a wide range of internal and external factors. Information obtained by enterprises using a systematic approach is used to model the current situation on the labor market and predict the prospects for the functioning of the team through the implementation of various marketing solutions (Platoshina, 2016). As part of the marketing approach, we focus on SNW and SWOT tools that are focused on identifying factors and threats, as well as recruitment and selection processes. The segmentation approach allows you to find market share and determine the objects that are targeted by the marketing activities of enterprises in search of personnel. The choice of approach to the research of personnel marketing is determined by the goals, the content of tasks, the presence or absence of information on the enterprise - object of research. Today, the development of a methodological platform and methodological tools for cognitive personnel marketing in both theoretical and practical aspects is at an early stage.

\section{RESULTS}

We are interested in cognitive modeling in so far as its application determines the growth of efficiency of management decisions for the enterprise as a whole and in the field of personnel marketing, in particular. There is no universal algorithm for developing solutions. The mentioned methodological approaches, continuing and developing each other, have a greater effect when they are applied together in an organic unity. The elements of personnel marketing technology are: selection, adaptation, regulation, evaluation and certification, training, rotation, motivation, staff release, budgeting and personal plans of personnel, and we use cognitive modeling for transparency of the personnel marketing technologies used (Figure 2).

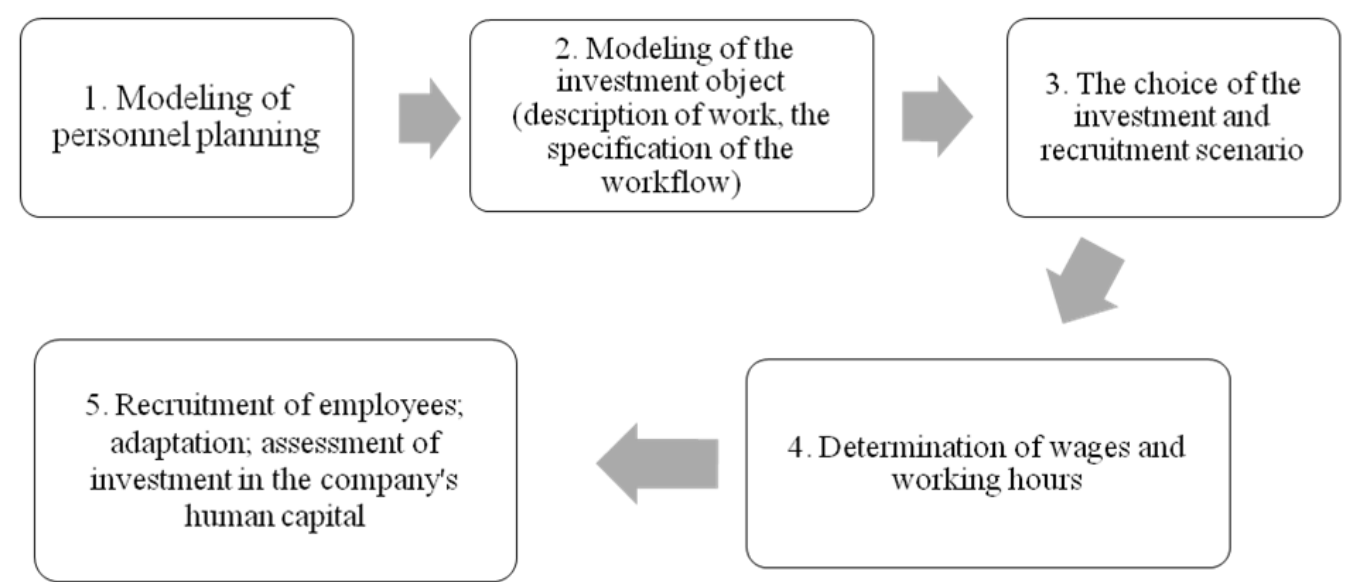

Figure 2: Cognitive Map of the Company's Investment Program.

We believe that this program should be implemented by line managers, HR managers and top management of the company. The division of functions by stages and content should differ depending on the type of enterprise, since the sources of recruitment are diversified. Labor evaluation, training, training and retraining should also be included in the personnel marketing system (Solovyov, 2015; Vanyan and Demyanchenko, 2016).

One of the manifestations of the communication function of personnel marketing is the implementation of links within the enterprise. Their task is to highlight the informal elements of relations in the enterprise. The company's staff develops a positive image of the employer. It can affect the consolidation of human resources within the enterprise, work 
on its improvement outside the enterprise, since the staff is considered as a carrier of goodwill (Rozhkova, 2018; Semina, 2017; Kropivnitsky, 2011).

The information function of HR marketing is to create an information field that is the basis for planning in the field of market segmentation and communications by target groups. It can be differentiated into: the study of requirements for positions and jobs; research of the external and internal environment of the enterprise; monitoring of the labor market and the image of the employer.

Personnel-marketing allows you to collect information for personnel planning, research information about the requirements that are imposed on the labor market to the positions of employees, to jobs; about the external and internal environment of the enterprise; labor markets and the image of the enterprise.

Sources of personnel information are: relevant legal acts; Analytics of Rossstat; employment and employment services; Internet; advertising within the industry, region, macro region; interviews with candidates; information of subjects of the educational services market; conversations with representatives of the business community; surveys of their own staff. We agree with those authors who believe that the information function of personnel marketing involves studying the requirements that candidates for vacant positions have for their profession, position and workplace. These include: knowledge, skills, experience, personal competence of the applicant, motivation, sphere of interests, values, learning ability, stress tolerance, etc. Implementation of the information function of personnel marketing is impossible without research of internal and external labor markets, personnel structure, their motivational attitudes, business processes, corporate culture, etc.

An important stage is to study the image of the employer from the point of view of competitors. The information function of personnel marketing allows you to identify areas where problems with personnel may occur and take timely preventive measures. Marketing information system in personnel management is a system of information exchange that allows personnel marketing specialists to analyze, plan and implement marketing activities. The basis of the system of marketing information on personnel is the sources of this information, namely:

- Educational programs and graduation plans of students from educational institutions;

- Training programs for additional training in commercial training centers and for retraining and advanced training courses at the labor exchange;

- Analytical materials of state bodies on labor and employment;

- Information messages from employment services, etc (Gorbunova and Khmeleva, 2017; Temirtayeva, 2020).

Monitoring the requirements for jobs forms a system of requirements that the company makes to the personnel applying for vacant jobs. Requirements for personnel are expressed in groups of parameters and are determined by the nature of work. Level of education; necessary knowledge; practical skills in a particular field of professional activity; experience in certain positions; skills of cooperation and mutual assistance: these characteristics of the candidate reflect their abilities. Personal qualities, stress resistance; ability to concentrate: these characteristics of the candidate reflect their properties (Platoshina, 2016; Kropivnitsky, 2011; Mishchenko, 2020). The desire for self-expression and self-realization; the ability to learn; interest in work, clarity of understanding of the trajectory of their own career: these characteristics of the candidate reflect their motivational attitudes. 
Requirements for the position are reflected in the company's regulatory documents:

- Job description, including the organizational status of the position, professional duties, rights, relationships of the position or workplace;

- Job specifications that reflect the personal characteristics required for the job;

- A qualification card that includes information about General and special education, work skills;

- A map of competencies that describes personal characteristics, abilities to perform official functions, and the type of behavior of employees.

The next set of personnel marketing problems is related to labor market research. The potential of the labor force covers both the external and internal labor market. The areas of analysis of the external labor market are focused on the structure of the labor market, including sector, regional, age, qualification; staff mobility; sources of covering the need for personnel; ways to cover the need for personnel; the behavior of competitors in the labor market: the cost of personnel. Monitoring these areas allows you to determine the quantitative and qualitative state of demand for personnel and its supply (Stepchenko and Khodyreva, 2014; Sergienko and Pisareva, 2018; Vanyan and Demyanchenko, 2016).

Marketing and diagnostics of the labor market form the company's communication system with sources of covering the need for personnel. Monitoring of external and internal labor markets serves as a basis for the development of these communication links between the enterprise and the subjects of the labor market.

Another set of personnel marketing problems is related to the study of the company's image, which provides the employer's goodwill, i.e. provides the company with advantages in terms of actually working staff.

The company's goodwill is formed by external influence from the competitive environment, as well as the peculiarities of corporate culture. Indicators, in our opinion, of the company's goodwill are:

- Conducting a survey of opinions of the company's staff, its partners, consumers, etc.;

- Monitoring of recruitment technologies, especially "failed" recruitment and selection activities;

- Monitoring of complaints from the staff;

- Monitoring and diagnostics of labor markets (city, region, macro region, etc.) and, first of all, the youth segments of these markets (Proskuryakov, 2016; Kretova and Mitina, 2017).

In our opinion, using the information function of personnel marketing, it is advisable to identify areas that complicate the long-term provision of the enterprise with labor resources. These include distortions in the labor markets, "destroyed" goodwill of the enterprise, unbalanced professional structure, etc.

Another set of personnel marketing problems is related to the communication function of the employer. The purpose of communication activities is to establish contact with the subjects of the labor market. Communication is being established both with the external labor market and with employees. The objects of the communication function are:

- The company's personnel who act as a participant in the internal labor market, as well as the bearer of its goodwill;

- External labor market as an environment for potential replenishment of the candidates ' electorate; 
- Transparency of the management system as a basic condition for influencing the formation of goodwill of the enterprise.

- Segmentation of labor markets (including the internal labor market (enterprise staff) and external labor markets).

In our opinion, segmentation is a process of decomposition, in which the demand for staff is separated from the supply of staff.

The methods of segmentation of the labor market include factor and cluster estimates. Factor estimation is based on criteria for forming target groups, which include geographical, demographic, economic, psychographic, and behavioral criteria (Abdurakhmanov, 2019; Kublin et al., 2019). The cluster assessment is based on the characteristics of carriers by age, gender, marital status, level of education, etc. Effective segmentation provides the definition of the subject of communication between the employer and the labor market through the formalization and application of transparent algorithms for covering personnel needs. At the same time, the main thing in the development of human resources is to achieve strategically set goals by implementing innovative HR technologies. We update the solution of personnel marketing tasks based on innovative HR technologies using another cognitive model. Here marketing communications aimed at: analyzing the labor market and developing specialized recommendations; calculating the cost of recruitment and selection of personnel; developing a program for attracting new employees and improving working conditions; encouraging employees for quality work; organization of training and team building for the team; interaction with the media and informal leaders, etc.

\section{DISCUSSION}

We agree with Ivanov and Petrov that the key conditions for the development of HR marketing should include (Figure 3).

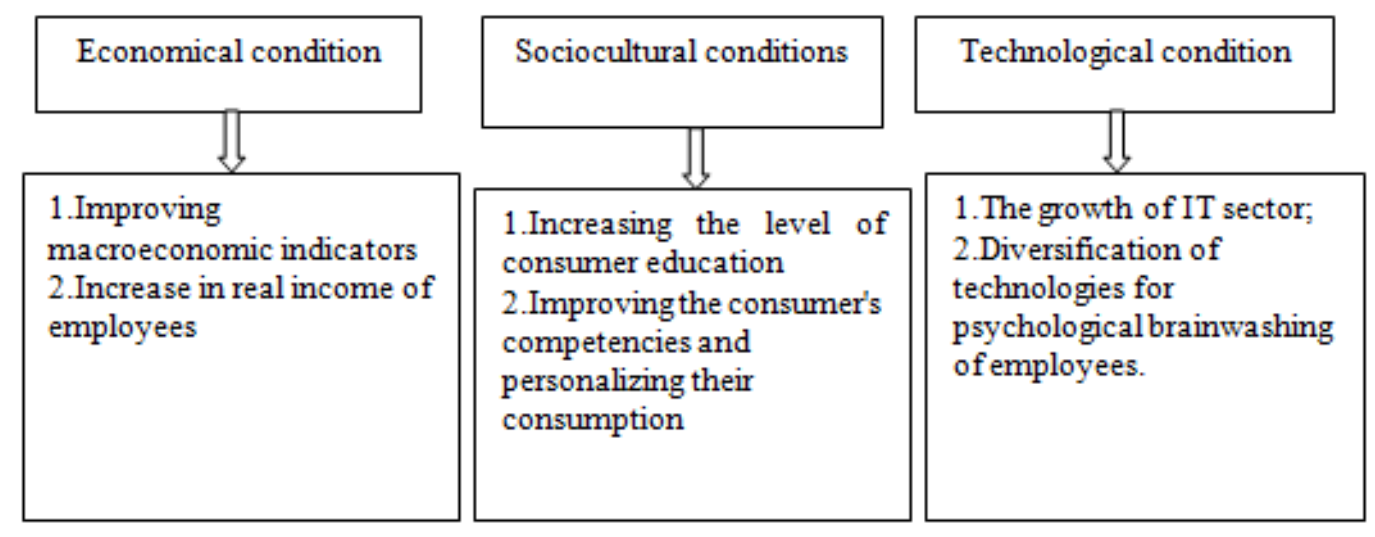

Figure 3: Conditions for the Development of Personnel Marketing.

We believe that cognitive modeling activates the imaginative thinking of employees and thus contributes to the emergence of new ideas. It expands and clarifies the goals set for the staff, contributes to the identification of tasks to be solved and projects to be implemented. Today, cognitive computer modeling is widely used in the field of marketing cognitive maps-a model presented in the form of a graph that allows you to describe the subjective perception of an employee or team of a particular problem (Rozhkova and Chashchin 2018; Sardak, 2012). The implementation of market research of the labor market in the process of forming the company's personnel allows you to timely meet the needs of the company in personnel, increase productivity and ensure its goodwill in the labor market. 
We share the scientific views of Ivanov and Petrov, according to which it is legitimate to distinguish the following components of HR marketing:

- Development of quality requirements for personnel;

- Determining the quantitative and qualitative need for personnel;

- Calculation of costs for selection, selection, hiring and use of personnel;

- Choice of ways to cover the need for personnel;

- Personnel assessment;

- Audit of the efficiency of the distribution staff.

The final set of problems of personnel management is related to the sources of covering the need for personnel. We will refer to external sources of covering the needs of professional infrastructure (universities, technical schools, schools, labor exchanges, outsourcing, etc.). Internal sources will include elements of self-sufficiency of the company's personnel needs (rotation, Institute of curatorship, Institute of mentoring, etc.).

\section{CONCLUSIONS}

So, the level of development of personnel marketing allows you to clearly respond to changes in the labor market and conduct active and competitive personnel activities. Business leaders should remember that it is necessary to create comfortable working conditions, since the prospects for business growth often depend on the ability of employees to adapt to unpredictable economic processes. This fact was clearly felt by representatives of the business community during the COVID-19 pandemic.

\section{REFERENCES}

1. Abdurakhmanov, A.A. Influence of integrated marketing communications (IMC) on consumer behavior. Economics: yesterday, today, tomorrow 9(3-1) (2019) 529-535.

2. Gorbunova, O.A, Khmeleva, K.E. Strategic analysis of personnel in the system of internal marketing. Bulletin of the Samara Polytechnic Institute 2 (2017) 76-86.

3. Kopylova, Yu.V. Marketing of personnel in human resource management. European Social Science Journal 7 (2017) 89-94.

4. Kretova, N.N., Mitina, N.N. Features of personnel marketing implementation in modern Russian conditions. Bulletin of Volgograd state University. Series 3: Economics. Ecology 19(2(39)) (2017) 88-96.

5. Kropivnitsky, Yu.G. Consensual approach to the definition of "marketing personnel". Bulletin of Khmelnytskyi national University 1 (2011) 150-153.

6. Kublin, I.M., Plekhanov, S.V. Ryabchenko, A.., Ludovic, E.E. Innovative tactical marketing approaches: features, accounting and analysis of efficiency. Economics of sustainable development 3(39) (2019) 129-133.

7. Mishchenko, T.L. Marketing in the organization's personnel management. Eurasian scientific community 1-3(59) (2020) 216220.

8. Platoshina, G.G. Strategic marketing of higher education. Economics of education 4 (2016) 14-20. 
9. Proskuryakov, V.V. Development of marketing strategies for competitive enterprise development. Science and business: ways of development 4 (2016) 118-123.

10. Rana, Renu and Shikha. Kapoor. "Exploring the contribution of employer branding in corporate image building." International Journal of Business and General Management (2016): 37-42.

11. Rozhkova, M.V. Marketing of personnel in the reporting system on the labor market. Economics: yesterday, today, head $8(11 a)(2018) 166-172$.

12. Rozhkova, M.V., Chashchin, V.V. Trust in marketing relationship: theoretical and practical aspects. Economics: yesterday, head 8(11a) (2018) 114-122.

13. Sardak, O.V. Integrating entrepreneurship to entrepreneurship to HR-marketing of entrepreneurship. Visnic Nachalovskoe University of water and nature domination. Series "Economy" 4(52) (2012) 202-209.

14. Semina, N.A. Theoretical bases of personnel marketing and its effectiveness. Agro-Food policy of Russia 8(68) (2017) 98-101.

15. Sergienko, E.S., Pisareva, E.V. Marketing approach to personnel management: problems and solutions. Economics and management: scientific and practical journal 4(142) (2018) 127-131.

16. Solovyov, B.A. Marketing research-the basis of the University's strategy. Bulletin of the Plekhanov Russian Academy of Economics 6 (2015) 3-9.

17. Soni, Anil Kumar, and Dharmender. Singh. "A study on cooperative marketing with reference of Chhattisgarh markfed limited." International Journal of Sales \& Marketing Management Research and Development 3.1 (2013): 35-44.

18. Stepchenko, T.S., Khodyreva, T.V. Specifics and features of marketing communications in the field of education. Economics and entrepreneurship 11-2(52) (2014) 414-419.

19. Singh, Komal, and Akshay Deokar. "Effects of 5 S Implementation on Performance of Organization." International Journal of Business and General Management (IJBGM) 7.2 (2018): 1-14.

20. Temirtayeva, A.T. Marketing technologies in the personnel selection system. Scientific and practical research 1-3(24) (2020) 249-252.

21. Vanyan, M.N., Demyanchenko, N.V. Personnel Involvement as an effect of marketing activities in the attitude of employees of the enterprise. Economics of sustainable development 1(25) (2016) 71-79.

22. Vijay, Swati. "A Study of Impact on Employment in Organised and Unorganised Retail Sector with Special Reference to Maharashtra State." International Journal of Human Resource Management 4.2 (2015): 1-10. 